\title{
IDENTIFIKASI FAKTOR PENYEBAB KERUSAKAN KAWASAN HUTAN ALAM PADA HUTAN PENDIDIKAN ANGGORI MANOKWARI
}

\section{(Identifying Factors Leading to Forest Stand Disturbances in the Educational Natural Forest Area of Anggori, Manokwari)}

\author{
FERNANDO K. YEMBISE ${ }^{1}$, REINARDUS L CABUY ${ }^{1 凶}$, ALFREDO O. WANMA $^{1}$ \\ ${ }^{1}$ Jurusan Kehutanan, Fakultas Kehutanan Universitas Papua Manokwari, Papua Barat, 98314. \\ Tlp/Fax: +62986211065. \\ $\square$ Penulis Korespondensi: Email: reinnardcabuy@gmail.com \\ Diterima: 12 Nov 2020| Disetujui:15 Des 2020
}

\begin{abstract}
Abstrak. Penelitian ini dilakukan dengan tujuan untuk memperoleh informasi terkini terkait perubahan kawasan hutan alam pada hutan Pendidikan Anggori Maokwari. Dalam kajian ini, pengumpulan informasi terkait bentuk kerusakan hutan dilakukan melalui kegiatan tracking dan mengidentifikasi bentuk-bentuk kerusakan yang diakibatkan menjadi penting untuk diketahui. Selain itu diskusi dan wawancara semi structural juga dilakukan guna memperoleh persepsi dan pandangan sosial masyarakat terkait interaksinya dengan hutan alam. Dari hasil penelitian diperoleh informasi bahwa telah terjadi perubahan kepada kawasan hutan alam dengan beberapa penyebab aktivitas antara lain: 1) aktivitas berkebun, 2) aktivitas pembukaan rencana lokasi wisata, 3) aktivitas penebangan untuk memperoleh kayu konstruksi dan kayu bakar, serta 4) aktivitas pembukaan jalan guna akses penduduk. Hasil analisis intensitas kerusakan diperoleh bahwa kerusakan yang terjadi masih cukup kecil dengan intensitas sebesar $9,685 \%$ atau sekitar 7,942 Ha dari total luasan yang ada.
\end{abstract}

Kata unci: Intensitas kerusakan, hutan alam, pemanfaatan lahan, interaksi, penduduk lokal

\begin{abstract}
This study aimed at gathering current information regarding forest land use changes in the natural forest of Anggori educational forest in Manokwari. In the study, information was obtained in regard to types of forest disturbance through tracking activity inside the forest area in order to identify types of disturbance which was important to unveil. In addition, discussion and semi structural interview were also carried out to notice how local inhabitants were interacted to the natural forest. The result found that changes have occurred to the natural forest in several disturbing ways such as 1) forest land opening for garden, 2) forest land opening for tourism park (close to the sea), 3) cutting off standing trees for house construction and firewood, 4) forest land opening that was intended for road and accessibility. However, form the disturbing intensity measurement indicated that the overall manleading disturbances in the natural forest was still low in percentage (9.685\%) or about $7.942 \mathrm{Ha}$ from the exited total natural forest area.
\end{abstract}

Keywords: Disturbing intensity, natural forest, land use, interaction, local inhabitants

\section{PENDAHULUAN}

Pertumbuhan dan perkembangan dunia terus terjadi dengan ekspansi pemanfaatan berbagai sumberdaya yang tersedia. Namum disisi lain, ketersediaan kebutuhan baik dasar maupun tambahan terus mengalami kemunduran terutama kebutuhan yang bersifat irreversible. Menyikapi kondisi ini, implementasi inovasi dan aplikasi teknolgi turut membatu dalam rangka mencari solusi guna pemenuhan 
kebutuhan dasar manusia seperti tempat tinggal, tempat mencari makan, tempat berinteraksi dan tempat pemenuhan kebutuhan tambahan lainnya seperti rekreasi wisata. Salah satu kebutuhan dasar manusia yang telah ada sejak lama ialah kebutuhan akan lahan yang selanjutnya dapat dikonversi menjadi media pemenuhan kebutuhan dasar seperti pendirian tempat tinggi yang layak, pengembangan usaha pertanian untuk pemenuhan kebutuhan pangan harian serta beberapa sebagai media pemenuh beberapa kebutuhan lainnya yang secara tidak langsung berafiliasi erat dalam kehidupan manusia (Cabuy et al. 2013; Marwa et al. 2019).

Paradigma pemanfaatan lahan saat ini telah mengalami pergeseran yang semula pemanfaatan lahan lebih banyak diperuntukan kepada Kawasan yang tidak berhutan dan atau tidak produktif, namun sekarang justru pemanfataan lahan pada areal berhutan dengan status hutan alam. Maraknya kecenderungan ini dikarenakan kebutuhan lahan yang terus ada pada berbagai lapisan kehidupan masyarakat. Sebagian besar hutan saat ini telah dirambah, dibuka dan dikonversi untuk pemenuhan kebutuhan masyarakat serta korporasi. Dengan hadirnya praktek perambahan dan konversi areal berhutan menjadikan luasana hutan semakin berkurang dan secara keseluruhan turut mendegradasi manfaatan, keberadaan hutan bagi keseimbangan ekosistem alam dan kelangsungan manusia disekitarnya.

Kabupaten Manokwari dengan luasan hutan 287,416 Ha (Badan Pusat Statistik Provinsi Papua Barat, 2020) merupakan salah satu reservoar keanekaragaman hutan dataran rendah di kepala burung Kepulauan New Guinea yang kaya akan biodiversitas. Namun di sisi lain, skenario atas dasar tuntutan ekonomi dan pemenuhan kebutuhan dasar akan lahan semakin masif terjadi dengan terus dilakukannya berbagai kegiatan perusakan hutan. Pada tahapan ini, terdapat kecenderungan gap understanding antara pemerintah daerah selaku eksekutor kebijakan pembangunan dan masyarakat dengan tuntutan kebutuhannya. Dasar ini yang mendorong penelitian ini perlu dilakukan guna mengidentifikasi secara langsung faktor-faktor penyebab kerusakan dan bentuk-bentuk kerusakan hutan yang telah terjadi di kawasan hutan alam yang dikelola oleh Fakultas Kehutanan Universitas Papua. Adapun tujuan dari penelitian ini adalah untuk mengidentifikasi bentuk-bentuk kerusakan dan faktor pendorong/penyebab terjadinya keruskaan serta intensitas luasan kerusakan yang terjadi di kawasan hutan alam Pendidikan Anggori Manokwari. Dengan dilakukannya penelitian ini selanjutnya dapat memberikan informasi tentang bentuk-bentuk kerusakan yang terjadi, faktor penyebab kerusakan serta intensitas kerusakan hutan alam sehingga dengan tersedianya informasi ini dapat dilakukan langkah dan upaya-upaya manajemen yang lebih baik ke depannya.

\section{METODE PENELITIAN}

Penelitian ini dilakukan pada kawasan hutan alam yang berada pada areal hutan Pendidikan Anggori Kabupaten Manokwari dan berlangsung selama kurang lebih 1 bulan yang dimulai dari bulan Agustus sampai dengan bulan September tahun 2020.

\section{Metode Penelitian}

Metode yang digunakan dalam penelitian ini adalah metode deskriptif dengan teknik survei lapangan dan wawancara semi struktural dengan acuan kuisioner.

\section{Varabel Pengamatan}

Variabel utama yang diamati dalam penelitian yaitu berupa bentuk-bentuk kerusakan, intensitas luasan kerusakan akibat kegiatan antropogenik penduduk dan faktor pendorong penyebab terjadinya kerusakan di 
sekitar kawasan hutan alam Pendidikan Anggori Manokwari.

\section{Teknik Pengumpulan Data}

Data yang dikumpulkan dalam penelitian ini berupa data primer dan sekunder. Pengumpulan data primer dilakukan melalui kegiatan identifikasi lapangan dengan cara melihat dan mengidentifikasi bentuk-bentuk kegiatan penduduk pada Kawasan hutan alam. Proses identifikasi bentuk-bentuk kerusakan dilakukan dengan mengklasifikasikan bentuk kerusakan yang terilihat secara langsung dilapangan. Kemudian dari beberapa bentuk kerusakan tersebut, diukur dan diestimasi intensitas kerusakannya (luas kerusakan) dengan pendekatan deliniasi poligon kerusakan. Proses pengambilan data bentuk-bentuk kerusakan dilakukan baik usecara langsung melalui tracking di dalam hutan dan berdasarkan informasi dari stakeholder terkait tentang adanya perubahan/alih fungsi di sekitar hutan alam. Sementara data sekunder seperti laporan penelitian, skripsi, dll., diperoleh dari instansi terkait guna memperkaya informasi terkait kerusakan pada hutan alam di di area hutan Pendidikan Anggori Manokwari.

\section{Pengolahan dan Analsis Data}

Data hasil identifikasi bentuk-bentuk kerusakan kemudian diklasifikasi berdasarkan bentuk kerusakannya dan diolah secara tabulasi dan ditampilkan dalam bentuk tabel dan grafik. Data intensitas luasan kerusakan dihitung untuk tiap-tiap bentuk kerusakan yang teridentifikasi dengan membandingkan luasan yang teridentifikasi rusak/terkonversi dengan besaran total areal hutan alam pada hutan Pendidikan Anggori Manokwari yang selanjutnya dikalikan persen untuk mendapatkan persentase luasan kerusakan. Pendekatan umum yang digunakan berdasarkan formula Arsyad (1999) dalam Konom dkk. (2019) adalah sebagai berikut :

$$
\mathrm{IK}(\%)=\frac{\text { luas areal terkonversi }}{\text { luas keseluruhan } \text { kawasan }} \times 100
$$

Dimana, IK = Intensitas kerusakan hutan

\section{HASIL DAN PEMBAHASAN}

\section{Kondisi Umum Hutan Pendidikan Anggori}

Hutan Arboretum Pendidikan Anggori merupakan Aset dan secara manajemen pengelolaan milik Fakultas Kehutanan Universitas Papua, yang di tetapkan oleh Badan Pertanahan Nasional (BPN) No. 29 tanggal 06 Februari 1984. Hutan Pendidikan Anggori mempunyai luasan 121,2 Ha (BPN, 1984) 124 Ha (hasil pengukuran 2017) yang terdiri dari Hutan Tanaman (arboretum) $16 \mathrm{Ha}$, Hutan Alam 84 Ha, Kebun Percobaan 22,1 Ha, Hutan Pantai 700 m, dan Semak belukar 1,3 Ha.

Namun, dari hasil digitasi menggunakan software GIS (Fahutan UNIPA) PKL 2019, Hutan Pendidikan Anggori adalah $\pm 92 \mathrm{Ha}$ yang terdiri dari Hutan Alam dengan luas hutan $\pm 82 \mathrm{Ha}$, dan Hutan Tanaman (arboretum) dengan luas $\pm 10 \mathrm{Ha}$.

Batas wilayah Hutan Pendidikan Anggori adalah :

- Sebelah Utara : Berbatasan dengan Samudra Pasifik

- Sebelah Barat : Berbatasan dengan Kampung Cabang Dua

- Sebelah Timur: Berbatasan dengan Kampung Aipiri

- Sebelah Selatan : Berbatasan dengan TWA Gunung Meja

Secara geografis Hutan Pendidikan Anggori terletak pada koordinat $134^{\circ} 5^{\prime} 09^{\prime \prime}-134^{\circ} 6^{\prime} 03$ BT dan $0^{\circ} 49^{\prime} 58-0^{\circ} 50^{\prime} 56^{\prime \prime} \mathrm{LS}$.

\section{Potensi Hutan Pendidikan Anggori}

Kawasan Hutan PendidikanAnggori memiliki potensi beraneka ragam flora dan fauna khususnya pada Hutan Alam. 


\section{Flora}

Jenis-jenis komersil seperti : Matoa (Pometia sp.), Bintanggur (Callophyllum inophyllum L.), Merbau (Intsia bijuga), Pulai (Alstonia scholaris), juga terdapat jenis non kayu seperti : palem, rotan, anggrek, liana, dan lainnya.

\section{Fauna}

Beberapa jenis-jenis fauna yang terdapat pada kawasan Hutan Pendidikan Anggori :

1. Herpetofauna : Biawak (Varamus indicus), katak (Platymantis sp.) ular (Stegonotus cuculatus modestus).

2. Mamalia : kuskus (Phalanger sp.), tikus tanah (Echymipera sp.) kelalawar (Dopsonia minor).

3. Afi fauna : Nuri Bayan (Electus roratus), sungu hitam (Cocracina melaena), kukabura perut merah (Daceleo gaudichhaud), beo irian (Mino domonti), elang laut (Heliastur), kakatua jambul kuning (Cacatua galerita).

\section{Bentuk-Bentuk Kerusakan Hutan Alam}

Pemanfaatan Hutan Alam oleh masyarakat di kawasan Pendidikan Anggori ternyata telah berlangsung cukup lama dan berdasarkan hasil identifikasi dilapangan, ditemukan 5 bentuk kerusakan beruapa pemanfaatan areal hutan alam oleh aktivitas antropogenik yang menyebebakan terjadinya keruskaan pada hutan Alam Pendidikan Anggori. Bentuk-bentuk kerusakan tersebut antara lain: 1). sebagai tempat berkebun, 2). rencana lokasi wisata, 3). penebangan hutan untuk pemenuhan kebuthan kayu, 4). pembangunan jalan penghubung antara kampung dan 5). jalan sarad.

\section{Kebun}

Secara umum mata pencarian oleh masyarakat sekitar kawasan hutan alam khususnya masyarakat kampung Aipiri adalah sebagai petani dan nelayan. Maka masyarakat melakukan pembukaan lahan Hutan untuk menjadikan tempat berkebun untuk menanaman beberapa jenis komoditi unggulan pertanian baik komoditi jangka pendek dan menengah guna pemenuhan kebutuhan hidup sehari-hari. Adapun jenis tanaman yang di tanam antar lain singkong, pisang, umbi jalar, serei, rica, genemo dll. Namun ada juga masyarakat yang berasal dari area Pasir Putih yang kemudian datang dan berkebun di sekitar kawasan hutan alam Pendidikan Anggori yang secara teknis komunitas ini mendapatkan ijin dari Kepala Kampung Aipiri untuk berkebun di area tersebut. Kebun yang dibuat oleh masyarakat dapat di lihat pada gambar di bawah ini.

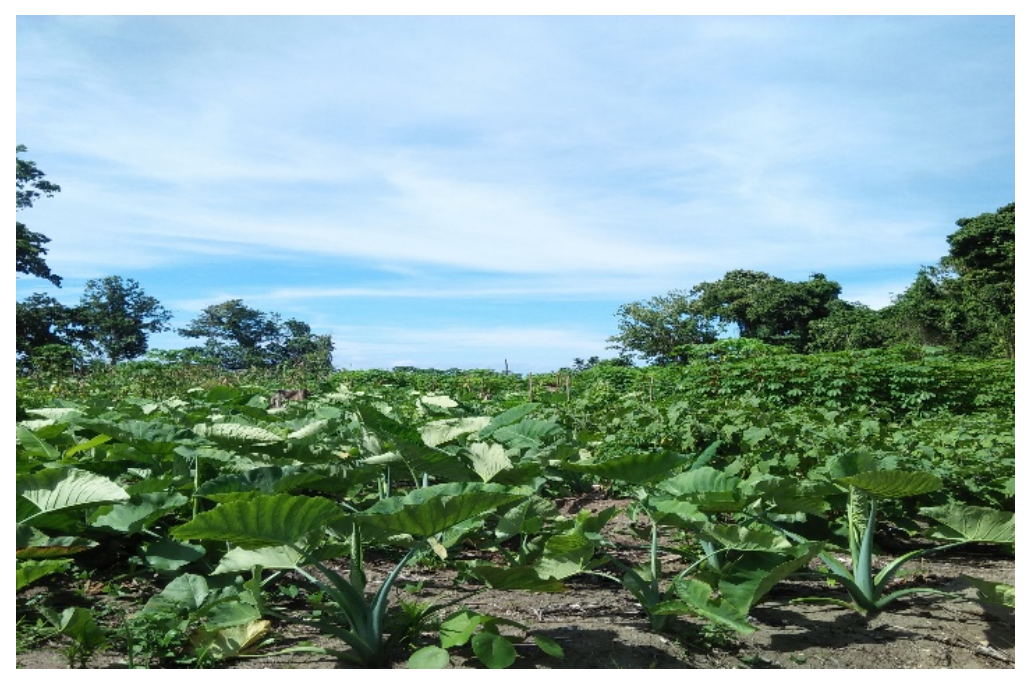

Gambar 1. Konversi lahan untuk kebun masyarakat pada kawasan hutan 


\section{Rencana Tempat Wisata}

Letak Hutan Alam Pendidikan Anggori yang luas kawasannya hingga mencampai pinggiran hutan pantai antara Kampung Aipiri dan Petrus Kafiar dengan keindahan pingiran hutan pantai dan laut yang cukup indah turut mendorong ekspansi hutan alam pada sekitar kawasan pesisir. Dari hasil penelitian memperlihatkan bahwa masyarakat di Kampung Aipiri memanfaatkan kawasan tersebut dengan melakukan pembukaan lahan hutan yang ternyata batas lahan tersebut masih berada dalam kawasan hutan alam Pendidikan anggori. Berdasarkan wawancara di lapangan juga bahwa masyarakat melakukan kegiatan tersebut berdasarkan perintah dari Kepala Kampung Aipiri atau pemilik hak ulayat yang kemudian lahan hutan pantai yang di buka itu selanjutnya dijadikan sebagai salah satu destinasi wisata alam. Adanya dorongan ini tentu masih berkorelasi dengan kegiatan ekonomi dimana dapat memberikan income tambahan bagi masyarakat di Kampung Aipiri.

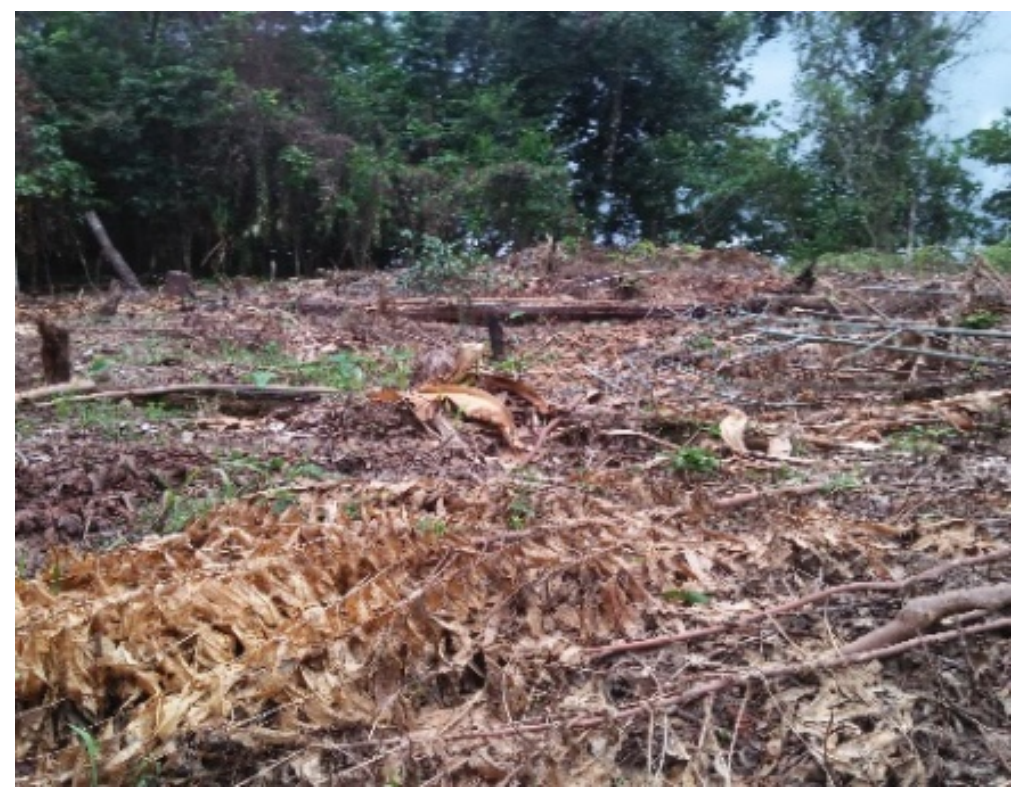

Gamabar 2. Rencana tempat Wisata

\section{Penebangan kayu}

Berdasarkan hasil identifikasi dan wawancara di lapangan diketahui telah terjadi pemanfaatan hutan alam dalam bentuk kegiatan penebangan kayu yang dilakukan di dalam kawasan Hutan Alam Pendidikan Anggori. Kegiatan ini dilakukan oleh masyarakat yang bermukim di sekitar kawasan hutan Alam yakni Kampung Aipiri. Hasil identifikasi menunjukkan bahwa masyarakat mengambil kayu atau menebang di dalam kawasan hutan alam Pendidikan Anggori untuk keperluan bahan konstruksi bangunan rumah. Disamping itu ada pula yang diambil untuk di jadikan sebagai kayu bakar dan beberapa kebutuhan lainnya seperti kendang ternak dll. Intensitas pengambilan kayu sebagai sumber bahan bakar (firewood) terlihat cukup tinggi dikarenakan kebutuhan konsumsi dengan cara memask secara konvensional dengan menggunakan tungku api. Secara umum jenis-jenis kayu yang ditebang dan dijadikan sebagai bahan bangunan rumah dan serta kayu bakar adalah jenis komersil seperti : Matoa (Pometia sp.), Merbau (Intsia bijuga), dan Pulai (Alstonia scholaris). 
Jejak aktivitas penebangan selanjutnya dapat di

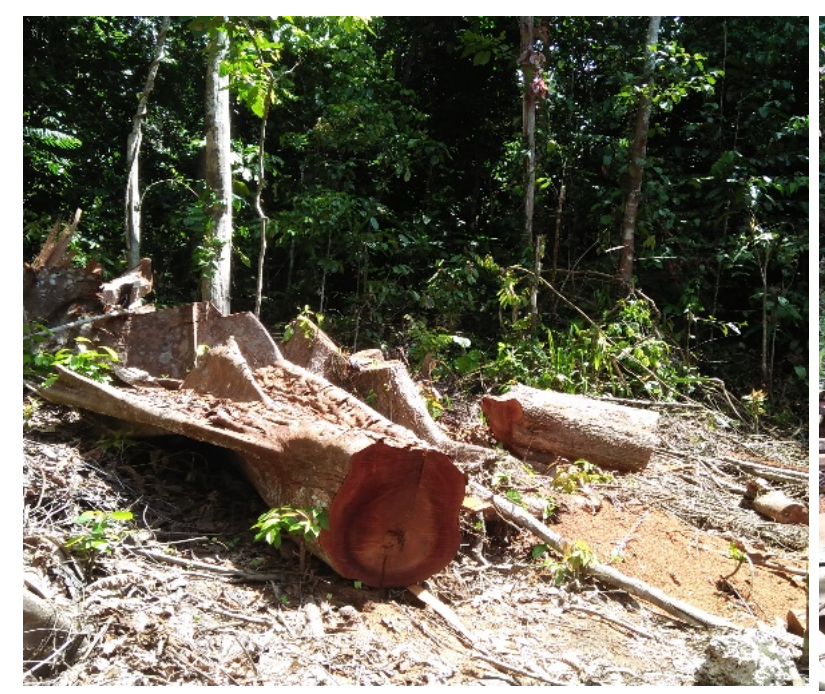

Gambar 3. Bekas tebangan jenis Pometia sp. dan jenis Alstonia sp. lihat pada gambar di bawah ini.

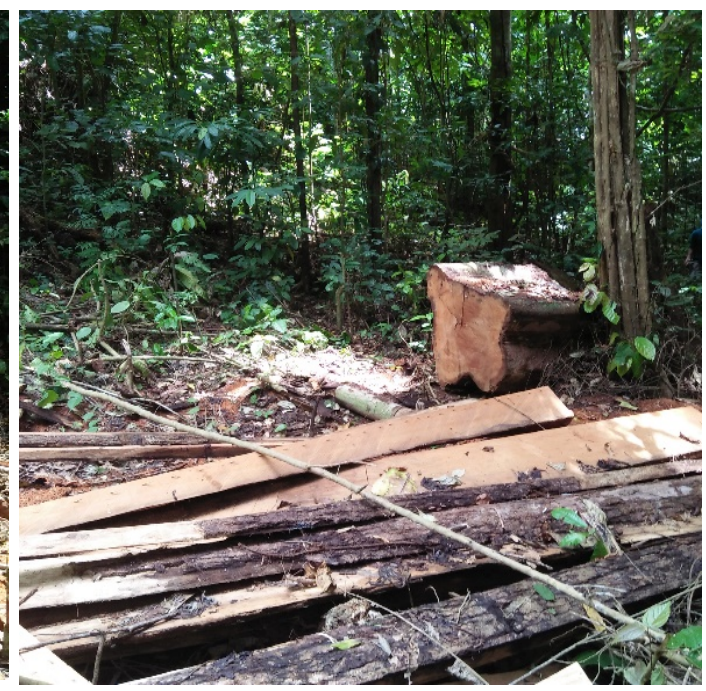

dan jalan penghubung antara kampung yang dibangun untuk menghubungkan akses kendaraan roda 4 dan roda 2 dari Kampung Aipiri menuju Kampung Petrus Kafiar atau sebaliknya yang mana rute dari jalan yang dibangun ini masuk dalam kawasan hutan alam Pendidikan Anggori. Jalan penghubung tersebut memiliki lebar dan panjang untuk jalan antara Kampung Aipiri menuju Petrus Kafiar memiliki panjang jalan mencapi \pm 714 meter dengan lebar jalan 5 meter dan kemudian jalan sarad yang ditemukan memiliki panjang \pm 447 meter dengan lebar jalan 4 meter. Jalan sarad ini di buat dengan tujuan sebagai jalur akses masuk dan keluar kendaraan roda 4 dan roda 2 untuk mengambil sortiment kayu hasil penebangan di dalam kawasan hutan alam Pendidikan Anggori. Dampak yang ditimbulkan dari pembangunan jalan ini adalah rusaknya hutan alam akibat pembukaan ahan hutan. Kondisi ini diperparah lagi dengan merambahnya pemukiman baru dan mempermudah akses ke dalam hutan melalui akses jalan yang dibuat tersebut.

4. Pembangunan Jalan

Dari hasil identifikasi di lapangan di temukan pembangunan jalan berupa jalan sarad 


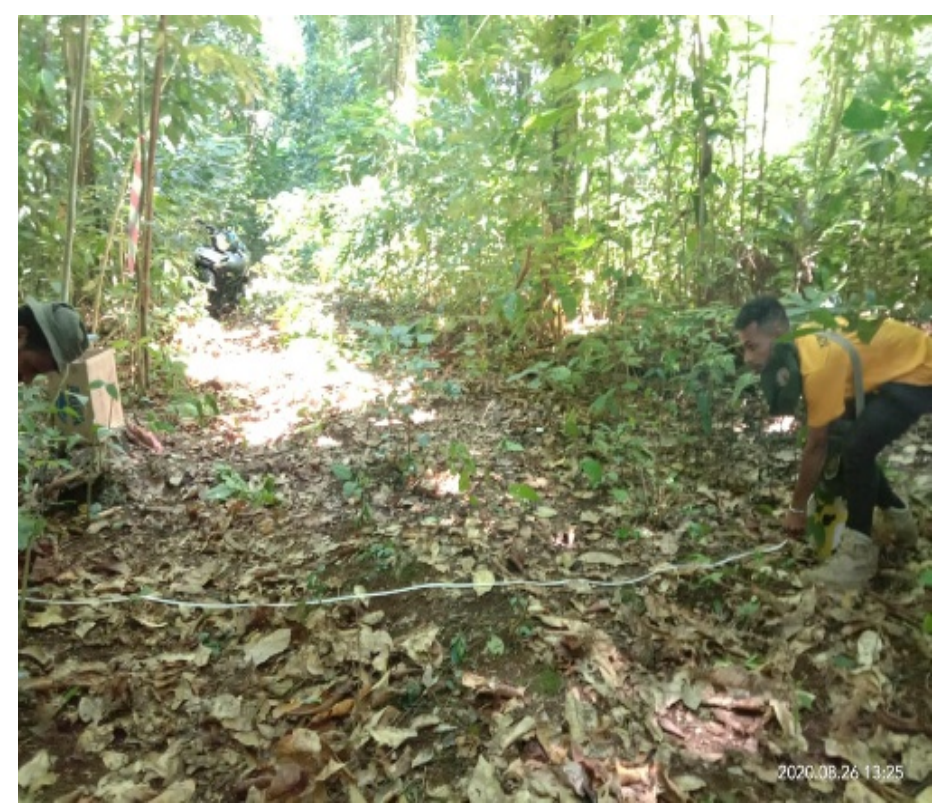

Gambar 4. Jalan sarad yang ditemukan di sekitar hutan alam

\section{Faktor Penyebab Kerusakan Hutan Alam}

Kondisi Hutan Alam Hutan Pendidikan Anggori sampai saat ini masih mengalami tekanan akibat pemanfaatannya yang kurang memperhatikan aspek kelestarian. Meningkatnya populasi penduduk serta tuntutan pembangunan yang lebih menekankan pada tujuan ekonomi masyarakat dengan mengutamakan infrastruktur fisik seperti melakukan konversi lahan hutan untuk memenuhui kebutuhan sehari-hari telah terbukti menjadi faktor penyebab kerusakan hutan alam pada Hutan Pendidikan Anggori. Sumber daya hutan merupakan sesuatu yang dapat membangkitkan kesejahteraan masyarakat melalui pemenuhan kebutuhan dasar (pangan, papan, sandang, papan) dan kebergunaannya bagi pihak lain. Berdasarkan hasil identifikasi di lapangan, kerusakan yang terjadi pada Hutan Alam secara dominan diakibatkan oleh aktifitas antropogenik. Kerusakan yang didorong oleh aktivitas atropogenik juga telah dilaporkan oleh Konom dkk (2019) di wilayah kabupaten Kaimana dimana persentasi kerusakannya cukup tinggi dengan berbagai jenis aktivitasnnya. Hasil identifikasi berdasarkan kuisioner kepada penduduk yang aktif berinteraksi dengan hutan alam, terlihat bahwa kehadiran hutan memberikan manfaat dalam pemenuhan kebutuhan hidup sehari-hari mereka. Manfaat hutan alam ini yang kemudian dikelola dan dikonversi untuk areal kebun, kemudian untuk pemenuhan kebutuhan kayu bakar dan konstruksi serta kebutuhankebutuhan harian lainnya.

Menurut Salghuna et al. (2018), bahwa terdapat beberapa strata gangguan akibat kegiatan antropogenik dengan bertambahnya populasi penduduk disekitar wilayah hutan seperti pembangunan, pertambangan dan perindustrian, illegal logging, perambahan hutan, penggembalaan, kebakaran hutan dan menyebabkan terjadinya penurunan tutupan hutan.

Masyarakat yang selalu berinteraksi dengan hutan alam Hutan Pendidikan Anggori merupakan masyarakat yang tinggal di sekitar 
hutan yaitu masyarakat kampung Aipiri di karenakan letak kampung Aipiri ini sangat berdekatan dengan batas Kawasan Hutan Alam Pendidikan Anggori. Masyrakat kampung Aipiri sebagian besar adalah bukan penduduk asli, tetapi masyarakat pendatang yang tinggal di Kampung Aipiri yang berasal dari suku suku Biak, Serui, Jawa, dan Manado. Namun Masyarakat asli kampung Aipiri sendiri adalah dari suku Arfak (Meyah).

Penyebaran penduduk kampung Aipiri sebanyak 418 jiwa yang terdiri dari 105 kepala keluarga (KK), (data monografi gereja 2019). Secara umum mata pencaharian masyarakat kampung Aipiri adalah sebagai nelayan dan petani. Namun bukan hanya masyarakat yang tingal di sekitar hutan alam Pendidikan anggori yang selalu melakukan interaksi dengan hutan tetapi ada juga yang berasal dari kampung pasir putih yang profesinya sebagai petani datang melakukan kegiatan pembukaan lahan hutan yang kemudian dijadikan lahan kebun sebagai tempat mata pencaharian untuk memenuhi kebutuhan sehari-hari.

Semakin bertambahnya jumlah penduduk yang bermukim di sekitar kawasan hutan Alam Pendidikan Anggori berdampak pada semakin besarnya tingkat kerusakan yang terjadi serta berkurangnya persentase luas kawasan alam yang diakibatkan oleh aktivitas manusia di dalam kawasan hutan (Konom dkk. 2019). Kondisi sosial dan ekonomi penduduk di sekitar kawasan hutan Alam Pendidikan Anggori sangat berpengaruh terhadap pertumbuhan ekosistem hutan alam. Adanya ketergantungan kehidupan masyarakat yang tinggal di sekitar hutan terhadap hutan Alam Pendidikan Anggori, dikarenakan hutan Alam Pendidikan Anggori dapat menyediakan kebutuhan kayu sebagai bahan bangunan, sumber kayu bakar, tempat bercocok tanam dan berkebun, maupun tempat berburu dll, yang semuanya bermuara pada usaha pemenuhan kebutuhan sehari-hari masyarakat tersebut
(Lekitoo et al. 2017). Terkait dengan kondisi tersebut, kegiatan ini pada akhirnya akan memanfaatkan hutan Alam secara tidak ramah lingkungan, dan dampaknya Hutan Alam Pendidikan Anggori akan terdegradasi dan rusak, bahkan sumber daya alam tersebut akan punah. Jong et al. (2017) menjelaskan bahwa perubahan tutupan hutan merupakan salah satu perubahan lingkungan kontemporer yang menentukan dan memvalidasi tingkat aktivitas manusia yang memiliki dampak global yang signifikan terhadap ekosistem bumi. Dari hal tersebut akan terlihat perubahan tutupan hutan melalui transisi hutan. Peristiwa saling mempengaruhi yang kompleks pada tutupan hutan, pertumbuhan penduduk, pembangunan ekonomi, permintaan akan barang dan jasa hutan dan tata kelola yang efektif adalah kekuatan pendorong transisi hutan.

\section{Intensitas Kerusakan Hutan Alam Pendidikan Anggori}

Interaksi antara masyarakat yang tingal disekitar kawasan hutan alam dapat dilihat dari besarnya ketergantungan masyarakat terhadap hutan alam tersebut. Berdasarkan data yang diambil di lapangan, diketahui hampir setiap hari penduduk yang tinggal sekitar kawasan ini berinteraksi dengan hutan Alam. Hal ini dikarenakan hutan alam memberikan banyak manfaat bagi masyarakat, sehingga untuk memenuhi kebutuhan hidup mereka sehari-hari masyarakat menggantungkan hidupnya pada hutan alam. Kegiatan masyarakat yang tingal sekitar kawasan hutan alam pada prinsipnya selalu memanfaatkan sumber daya alam di sekitarnya yang memberikan banyak manfaat bagi kehidupan masyarakat setempat. Namun pada akhirnya dorongan pemanfaatan hutan yang tidak ramah lingkungan dan sustainable ini akan menyebabkan kawasan hutan menjadi terdegradasi, rusak, bahkan sumber keanekarakaman di dalamnya menjadi terancam punah. Dari hasil penelitian diperoleh 5 bentuk dan penyebab kerusakan pada areal hutan alam 
akibat aktivitas antropogenik atau manusia berdasarkan perhitungan intesintas kerusakan
(IK) yang dijabarkan dalam bentuk table $1 \mathrm{di}$ bawah ini.

Table 1. Bentuk dan intensitas kerusakan hutan alam pendidikan anggori

\begin{tabular}{|c|c|c|c|}
\hline No. & Bentuk Kerusakan & Luas (Ha) & $\mathrm{IK}(\%)$ \\
\hline 1 & Kebun & 4,975 & 6,067 \\
\hline 2 & Rencana Tempat Wisata & 2,391 & 2,916 \\
\hline 3 & Penebangan liar & 0,041 & 0,050 \\
\hline 4 & $\begin{array}{l}\text { Jalan penghubung antar } \\
\text { kampung }\end{array}$ & 0,357 & 0,435 \\
\hline 5 & Jalan Sarad & 0,178 & 0,217 \\
\hline & Total & 7,942 & 9,685 \\
\hline
\end{tabular}

Sumber data primer, 2020

Tabel 1 menunjukkan bentuk dan intensitas kerusakan yang berbeda-beda untuk setiap jenis kerusakan yang disebabkan oleh aktivitas antropogenik pada Kawasan Hutan Alam Pendidikan Anggori. Total intensitas kerusakan hutan alam terbesar yaitu berupa konversi lahan untuk kebun dengan luasan mencapai 4,975 $\mathrm{Ha}$
(6,067\%), disusul oleh bentuk kerusakan untuk pembukaan tempat wisata sebesar 2,391 $\mathrm{Ha}$ $(2,916 \%)$. Sementara bentuk dan intensitas kerusakan terkecil ialah jenis kerusakan yang disebabkan oleh kegiatan penebangan liar yaitu seluas $0,041 \mathrm{Ha}(0,05 \%)$ dari kerusakan yang ada di kawasan hutan alam.

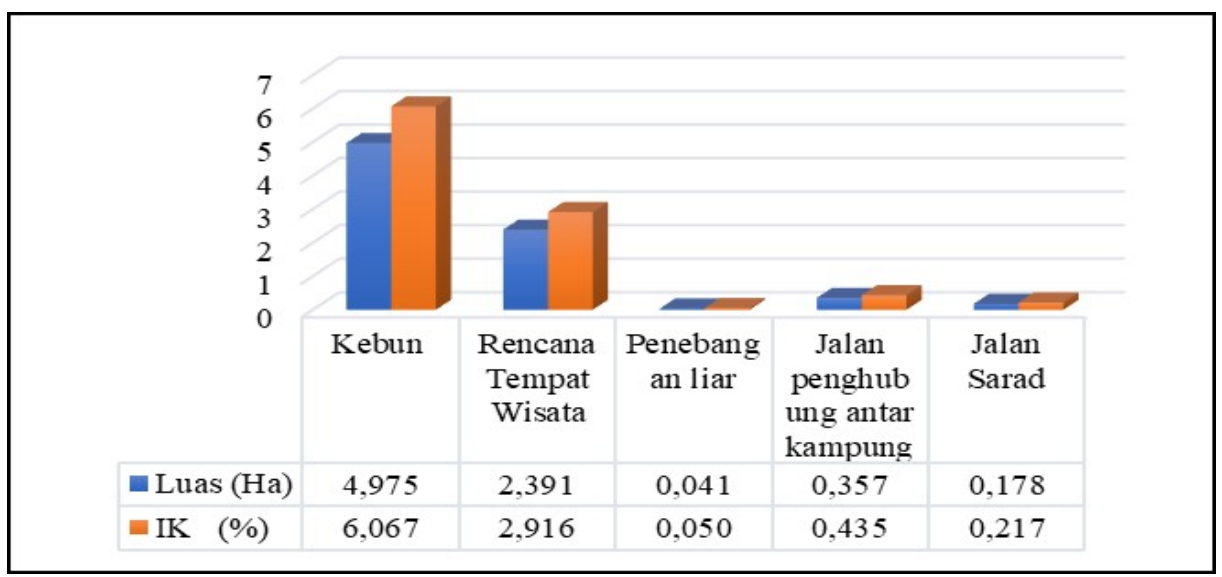

Gambar 5. Jenis dan intensitas kerusakan areal hutan Alam

Secara umum, adanya beberapa kerusakan tersebut sanggat berpengaruh terhadap keseimbangan dan ekosistem hutan alam, namun secara luasan tidak terlalu berdampak signifikan karena dari selisih luasan dan intensitas kerusakannya masih tergolong cukup kecil yang apabila didasarkan pada hasil digitasi menggunakan software GIS (Fahutan
UNIPA) PKL 2019, luasan hutan alam pada Hutan Pendidikan Anggori adalah $\pm 82 \mathrm{Ha}$. Dengan demikina ada terjadi kerusakan dengan luasan mencapai $\pm 74 \mathrm{Ha}$. Gambar di bawah ini menunjukkan beberapa bentuk kerusakan yang terlihat secara visual pada mapping yang di buat. 


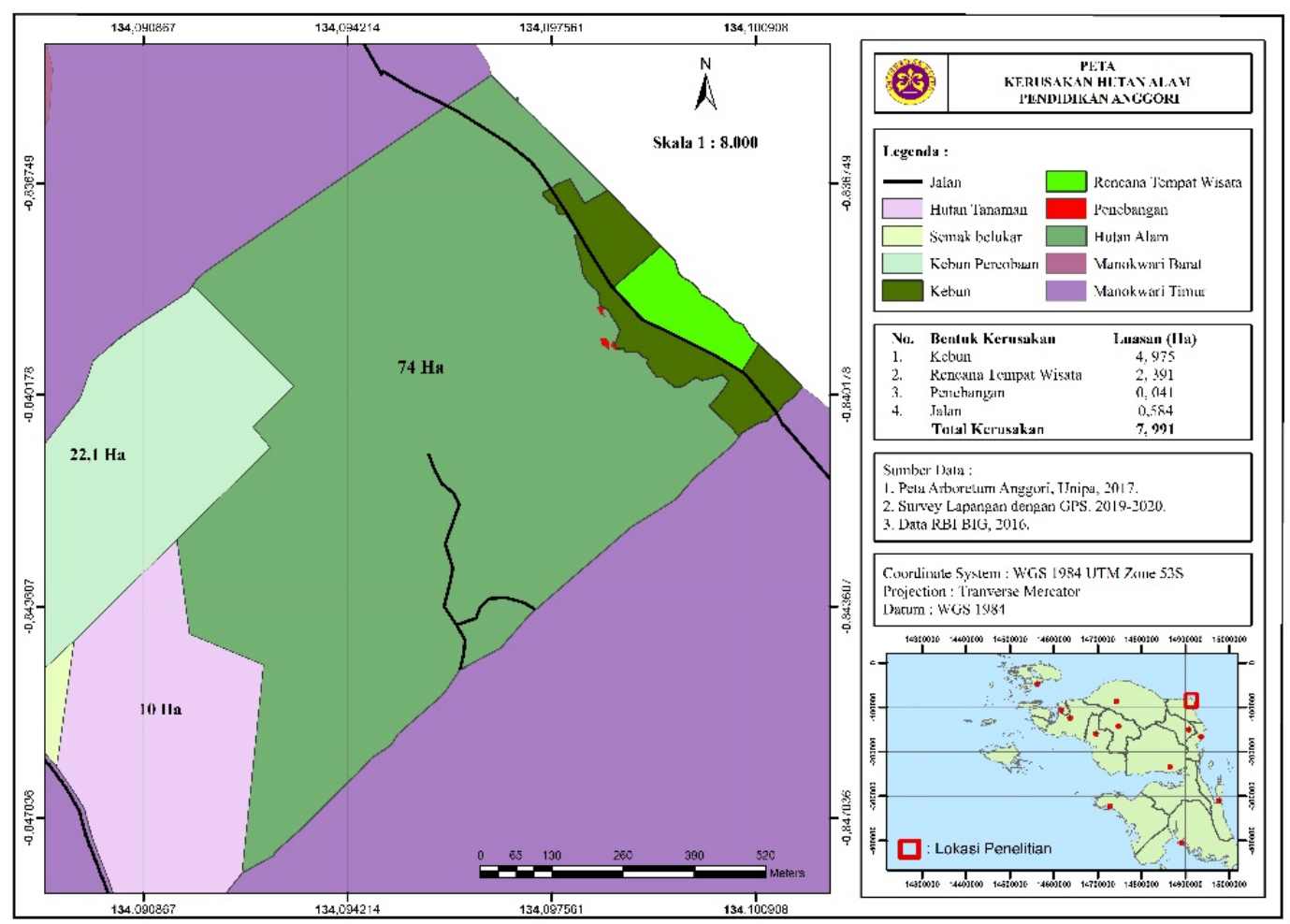

Gambar 6. Bentuk-bentuk kerusakan yang terjadi pada kawasan hutan alam Pendidikan Anggori

\section{Kriteria Kerusakan Hutan Alam}

Kriteria baku kerusakan hutan alam pada Hutan Pendidikan Anggori Manokwari ditetapkan berdasarkan persentase luas tutupan dan kerapatan individu pohon perhektarnya yang masih teridentifikasi pada kawasan hutan alam. Standar baku pengukuran yang digunakan dalam penelitian di hutan alam ini masih mengacu pada standar baku kerusakan hutan mangrove yang termuat di dalam Peraturan Menteri Lingkungan Hidup Nomor 201 tahun 2004 dengan standar baku kriteria sebagai berikut :

Tabel 2. Kriteria baku kerusakan hutan alam pada hutan Pendidikan Anggori

$$
\text { Kriteria Penutupan (\%) Kerapatan (Pohon/Ha) }
$$

\begin{tabular}{llcc}
\hline Baik & Sangat padat & $\geq 75$ & $\geq 1500$ \\
& Sedang & $\geq 50-<75$ & $\geq 1000-<1500$ \\
Rusak & Jarang & $<50$ & $<1000$ \\
\hline
\end{tabular}

Merujuk pada table kriteria baku di atas dan data hasil crushing serta interpretasi tutupan tajuk dapat disimpulkan bahwa secara keseluruhan kerapatan individu pohon per hektarnya masih cukup tinggi yakni melebihi 1.500 individu pohon dalam satu hekatar luasan. Jumlah ini mengacu pada hutan alam dengan komposisi hutan heterogen dan bukan 
untuk satu jenis tumbuhan. Hal ini perlu digaris bawahi mengingat pada kesatuan Kawasan hutan Pendidikan anggori, masih terdapat beberapa spot area yang ditumbuhi hanya dari satu jenis tanaman hutan. Sementara hasil interpretasi citra terkini yang dihimpun dari beberapa referensi mengindikasikan tutupan tajuk yang masih rapat dan kondisi ini menggambarkan persentasi tutupan tajuk yang cukup tinggi ( $\geq 75 \%$ ) pada area hutan alam. Sehingga dapat disimpukan bahwa tutupan tajuk pada Kawasan hutan alam masih tinggi atau cukup padat.

\section{DAFTARA PUSTAKA}

Badan Pusat Statistik Provinsi Papua Barat. 2020. Luas Kawasan hutan dan Perairan Menurut Kabupaten/Kota, 2010-2014. Diakses Pada 26 juni 2020. Dari https://papuabarat.bps.go.id/statictable/2015/ 03/18/116/luas-kawasan-hutan-dan-perairanmenurut-kabupaten-kota-2010---2014.html.

Cabuy RL, Marwa J, Manusawai $\mathrm{J}$ and Rahawarin YY. 2012. Non-woody plant species of Papuan island forest, a sustainable source of food for the local communities. Indian Journal of Traditional Knowledge, 11 (4): 586-592.

Jong WD, Galloway G, Katila P dan Pacheco P. 2017. Forestry discourses and forest based development - an introduction to the special issue. International Forestry Review, 19 (SI), DOI: $10.1505 / 146554817822407358$.

Konom NH, Cabuy RL, Wanma AO. 2019. Identifikasi kerusakan areal hutan mangrove akibat aktivitas penduduk di daerah Airtiba Kabupaten Kaimana. Jurnal Kehutanan $\begin{array}{lll}\text { Papuasia, } & 5 & \text { (2): } 153-163 \text {, }\end{array}$ https://doi.org/10.46703/jurnalpapuasia.Vo15 .Iss2.148.

Lekitoo K, Peday HFZ, Panambe N, Cabuy RL. 2017. Ecological and ethnobotanical facet of 'Kelapa Hutan' (Pandanus spp.) and perspectives towards its existence and benefit. International Journal of Botany. 13: 103-114.

Marwa J, Sardjono MA, Ruchaemi A, Devung S, Cabuy RL. 2019. Benefit sharing schema from the forest: Identifying potential distributions to customary communities in Teluk Bintuni district, Indonesia. Acta Universitatis Agriculturae Et Silviculturae Mendelianae Brunensis, 67 (4): 963-972. https://doi.org/10.11118/actaun2019670409 63.

Salghuna NN, Chandra PR and Kumari JA. 2018. Assessing the impact of land use and land cover changes on the remnant patches of Kondapalli reserve forest of the Eastern Ghats, Andhra Pradesh, Indi'. The Egyptian Journal of Remote Sensing and Space Sciences. National Authority for Remote Sensing and Space Sciences, pp. 1-11. doi: 10.1016/j.ejrs.2018.01.00. 